\section{International Scientific Journal Theoretical \& Applied Science}

\author{
p-ISSN: 2308-4944 (print) e-ISSN: 2409-0085 (online) \\ Year: $2015 \quad$ Issue: $05 \quad$ Volume: 25
}

Published: $30.05 .2015 \quad$ http://T-Science.org

SECTION 21. Pedagogy. Psychology. Innovations in the field of education.
Rauan Bermagambet

Master of Juridical Sciences

Senior Lecturer of the Department of History of

Kazakhstan, Basics of Law and Economics

Arkalyk State Pedagogical Institute named after

I.Altynsarin

Arkalyk, Kostanay region, Kazakhstan bermagambet@gmail.com

Makhabbat Kaukhanova

Senior Lecturer of the Department of

Physical Culture and Sports

Arkalyk State Pedagogical Institute named after

I.Altynsarin

Arkalyk, Kostanay region, Kazakhstan

77_mahonia_77@mail.ru

\title{
CONCEPTUAL BASES OF FORMATION OF LEGAL COMPETENCE OF THE FUTURE BACHELOR OF EDUCATION ON SPECIALTY 5B010800 - «PHYSICAL CULTURE AND SPORTS»
}

\author{
Abstract: The article is intended to describe some questions of the formation of legal competence of the future \\ Bachelor of Education on specialty 5B010800 - «Physical Culture and Sports» in the Republic of Kazakhstan. \\ Key words: legal competence, professionally-oriented competence, bachelor of education, physical culture \\ and sports, sports law, education law. \\ Language: Russian \\ Citation: Bermagambet R, Kaukhanova M (2015) CONCEPTUAL BASES OF FORMATION OF LEGAL \\ COMPETENCE OF THE FUTURE BACHELOR OF EDUCATION ON SPECIALTY 5B010800 - «PHYSICAL \\ CULTURE AND SPORTS». ISJ Theoretical \& Applied Science 05 (25): 160-164. \\ Soi: http://s-o-i.org/1.1/TAS*05(25)30 Doi: crossef http://dx.doi.org/10.15863/TAS.2015.05.25.30
}

\section{КОНЦЕПТУАЛЬНЫЕ ОСНОВЫ ФОРМИРОВАНИЯ ПРАВОВОЙ КОМПЕТЕНТНОСТИ БУДУЩЕГО БАКАЛАВРА ОБРАЗОВАНИЯ ПО СПЕЦИАЛЬНОСТИ БВО10800 - «ФИЗИЧЕСКАЯ КУЛЬТУРА И СПОРТ»}

Аннотация: В статье рассмотрены некоторые вопросы формирования правовой компетентности будущего бакалавра образования по спещииальности 5В010800 - «Физическая культура и спорт в Республике Казахстан.

Ключевые слова: правовая компетентность, профессионально-ориентированная компетентность, бакалавр образования, физическая культура и спорт, спортивное право, образовательное право.

В современном обществе образование играет важнейшую роль, поскольку представляет собой главную движущую силу общественного развития. Не случайно большое внимание со стороны государства уделяется проблемам образования, одна из которых - повышение его качества. Решение этой задачи в настоящее время связывается с реализацией компетентностного подхода как новой парадигмы образования [1].

Социальная значимость правового образования определяется задачами построения гражданского общества и правового государства. C обретением независимости в Республике Казахстан происходит существенная переоценка значимости права в общественной жизни. Об этом свидетельствуют повышение престижа юридических специальностей, возрастание интереса к значимой правовой информации. В научной литературе доминирует подход к праву как важнейшему социальному феномену. Правовая компетентность становится необходимым компонентом профессиональной компетентности специалиста любой сферы, сферы образования, в том числе, сферы физической культуры и спорта, позволяющим эффективно решать профессиональные задачи в соответствии с действующим правом.

В то же время, анализ сложившейся практики правовой подготовки специалиста в области физической культуры и спорта показал, что эта подготовка нередко ограничивается общетеоретическими дисциплинами, не 
позволяющими сформировать определённый комплекс умений, навыков и личностных качеств, необходимых для успешного трудоустройства и эффективной профессиональной деятельности. Традиционно в образовательных учреждениях, в том числе высших учебных заведениях приоритет отдаётся специальным дисциплинам. Вместе с тем, следует отметить, что недооценка значимости правовых дисциплин в профессиональной подготовке студента способна повлечь негативные последствия. Низкий уровень правовой компетентности, формирующейся, в том числе при изучении правовых дисциплин в вузе, может поставить выпускника в условия социальной незащищённости, сложной адаптации к дальнейшей профессиональной деятельности. Так, выпускник вуза с присвоенной академической степени «бакалавр образования» по специальности 5В010800 - «Физическая культура и спорт» нередко оказывается в трудной ситуации при решении правовых вопросов в сфере своей профессиональной деятельности. В то же время, к числу обязательных требований к работнику сферы образования относятся не только знание предмета, методики, педагогики, но и основ права, нормативных правовых актов в сфере образования и узкого профессионального профиля. В связи с этим формирование правовой компетентности следует рассматривать как неотъемлемую часть общего процесса становления профессиональной компетентности специалиста выше названной сферы.

Формирование правовой компетентности студентов - будущих бакалавров образования по специальности 5В010800 - «Физическая культура и спорт» в процессе профессиональной подготовки основывается на фундаментальных положениях педагогической, психологической и юридической наук.

В частности, вопросы, связанные с подготовкой высококвалифицированных специалистов в области физической культуры и спорта были посвящены диссертационные исследования казахстанских ученых: Калменов Г.Е. [2], Малай Л.Ю. [3], Сапарбаев М.Б. [4], Юмашева Ж.А. [5] и др.

Проблемы формирования правовой компетентности студентов, специалистов и др. в области физической культуры и спорта рассматриваются в исследованиях российских ученых: Агеев С.Л. [6], Воеводина С.С. [7], Кузнецов С.А. [8], Сибатрова М.А. [9], Точицкий А.В. [10], Феоктистова О.А. [11], Хурлет М.А. [12] и др.

При неоспоримой теоретической и практической значимости исследований указанных авторов, следует отметить, что в научной литературе нами не обнаружено ни одного исследования, посвящённого проблеме формирования правовой компетентности будущего бакалавра образования по специальности 5В010800 - «Физическая культура и спорт» в Республике Казахстан. Анализ литературы свидетельствует о том, что обучение праву этой категории студентов осуществляется с недостаточным учётом специфики их будущей профессиональной деятельности. При несомненном преимуществе имеющеея дисциплины «Основы права» следует отметить, что её учебно-методическое оснащение как количественно, так и качественно пока оставляет желать лучшего. Так, для студентов иных специальностей не существуют различные учебные издания по правовому обеспечению профессиональной деятельности, в том числе, и для студентов специальности 5В010800 «Физическая культура и спорт» нами не выявлено ни одного учебного издания по этой дисциплине, ориентированной именно на данную специальность.

Проведенный анализ точек зрения исследователей по вопросу профессиональной компетентности специалиста позволил сделать вывод о том, что правовая компетентность специалиста в области физической культуры и спорта как составная часть профессиональной компетентности не получила в казахстанской научной литературе необходимого отражения.

Под правовой компетентностью будущего бакалавра образования по специальности 5В010800 - «Физическая культура и спорт» мы понимаем совокупность качеств, отражающих степень квалификации, уровень правовых знаний, умений, навыков, готовности и способностей, необходимых для решения правовых вопросов в сфере профессиональной деятельности.

В структуре профессиональной компетентности студентов специальности 5В010800 - «Физическая культура и спорт» правовая компетентность должна занимать особое место.

В ГОСО (2010) по специальности 5В010800 - «Физическая культура и спорт» в пункте 6.9 «Требования к ключевым компетенциям бакалавра физической культуры и спорта» бакалавр по физической культуре и спорту должен знать правовые основы управления физической культурой и спортом; в пункте 8.1 «Требования к общей образованности» бакалавр должен владеть правовыми нормами, регулирующими отношение человека к человеку, обществу, окружающей среде; а также, в пункте 8.2 «Требования к социально-этическим компетенциям» бакалавру специальности «Физическая культура и спорт» необходимо знать правовые и нравственно-этические нормы в 
сфере профессиональной деятельности, спортивную этику [13].

Изложенные требования к уровню правовой подготовки бакалавра образования по специальности 5В010800 - «Физическая культура и спорт» позволяют выделить объективные факторы, определяющие структуру правовой компетентности:

- правовые знания;

- интеллектуальные и практические умения и навыки по толкованию и правильному применению правовых норм, лежащих в основе конкретного вида практической деятельности; система мировоззренческих и поведенческих качеств личности, являющихся основой убеждений и идеалов, необходимых для осуществления профессиональной деятельности в соответствии с законом;

- основные черты творческой деятельности, обеспечивающие эффективное решение проблем, совершенствование умений в контексте постоянно меняющегося законодательства.

Однако необходимо учесть тот факт, что вышеописанные требования в полной мере невозможно осуществить в рамках дисциплины обязательного компонента общеобразовательных дисциплин «Основы права». На данный момент, типовая учебная программа по данной дисциплине не предполагает профессиональноориентированный подход в рамках образовательных программ группы специальностей «Образование».

При формировании правовой компетентности студентов следует учитывать ряд существенных особенностей. Во-первых, принципиально важным является правильное понимание вопроса о месте и роли понятия профессии «педагог» и (или) работник сферы образования. В рамках требований ГОСО, под правовой компетентностью, а именно профессионально-ориентированной, мы можем понимать совокупность качеств, отражающих степень квалификации, уровень правовых знаний, умений, навыков, готовности и способностей, необходимых для решения правовых вопросов в сфере профессиональной деятельности работника сферы образования. Во-вторых, специальности группы специальностей «Образование», помимо объединяющих их сферы образования, рассматривает необходимость и возможность формирования у студентов (например, будущих бакалавров образования по специальности 5В010800 - «Физическая культура и спорт») профессионально-ориентированной правовой компетентности следующего, более узкого уровня, как например знания, умения и навыки законодательства Республики Казахстан в области физической культуры и спорта.
Проведённый анализ нормативных документов, в том числе Типовые квалификационные характеристики должностей педагогических работников и приравненных к ним лиц [14] показал, что в структуре профессиональной компетентности специалиста в области физической культуры и спорта правовая компетентность занимает особое место. В связи с этим в процессе формирования правовой компетентности студентов специальности целесообразно акцентировать их внимание на необходимость изучения правовых дисциплин и их значимость в профессиональной подготовке бакалавра, поскольку то, что является очевидным для студентов-юристов, не всегда бывает понятным для студентов неюридических специальностей. Именно поэтому совершенно необходима особая мотивация студентов, их заинтересованность в изучении права, в особенности профессионально-ориентированной сферы.

Следующей важной особенностью является наличие творческого (тактического) мышления студентов специальности 5В010800 «Физическая культура и спорт». Специфика образования в этой сфере проявляется в особенностях постижения профессии. Если образовательные программы по иным специальностям группы специальностей «Образование» (кроме специальностей 5В010600 - «Музыкальное образование» и 5В010700 «Изобразительное искусство и черчение») строятся, в основном, на научной базе по принципу перехода от общего фундаментального к специальному - частному, то освоение образовательных программ в сфере физической культуры и спорта в малой степени связано с изучением научных дисциплин и базируется на физических (творческих) способностях, данных человеку природой. Образовательный процесс у этих специальностей в большей степени связан с сугубо практическим чувственным, физическим и интеллектуальным постижением обучающимся сути осваиваемого вида деятельности, раскрытием психофизических возможностей личности. В связи с этим следует учитывать практическую направленность профессионального образования, предопределяющую характер подготовки специалистов физической культуры и спорта. Эту особенность преподавателю необходимо принимать во внимание, как при планировании, так и при проведении занятий по правовым дисциплинам, используя творческий потенциал студентов.

Общая тенденция такова, что в учебных планах увеличивается доля предметов, ориентированных на будущую профессию, то есть намечается тенденция к профессионально- 
ориентированному подходу. Частичная академическая автономность вузов в области самостоятельности в определении учебных программ позволяют определять профессионально-ориентированную траекторию при подготовке бакалавров образования по различным специальностям, в том числе и по специальности 5В010800 - «Физическая культура и спорт».

На данный момент, в рамках осуществления образовательной программы высшего образования по специальности 5В010800 «Физическая культура и спорт» предусмотрено прохождение дисциплины обязательного компонента общеобразовательных дисциплин «Основы права». В рамках типовой учебной программы по данной дисциплине не предусмотрен профессиональноориентированный подход в рамках различных специальностей группы специальностей «Образование». Достаточно небольшой объем часов по дисциплине, а также поточный подход в проведении лекционных занятий ограничивает профессионально-ориентированный подход при проведении занятий.

На примере Российской Федерации, мы можем констатировать тот факт, что по аналогичной специальности в блоке профессиональных дисциплин образовательной программе есть дисциплина «Правовые основы физической культуры и спорта» в объеме 90 часов [15].

В данный момент соотношение количества профессиональных (в том числе, междисциплинарных с юридическими науками) и правовых дисциплин в учебных планах подготовки бакалавров образования по специальности 5В010800 - «Физическая культура и спорт» не способствует полному осуществлению требований ГОСО по данной специальности.

Помимо общеобразовательной дисциплины «Основы права» вуз может определять (в случае академической свободы и не определять) дополнительные правовые дисциплины по специальности самостоятельно. При таком положении трудно обеспечить качественный уровень правового образования студентов и решать задачи профессиональной деятельности, предусмотренные в стандартах.

Мы считаем, что изучение одной правовой дисциплины недостаточно для будущей правоприменительной деятельности студентов. Предусмотренных в стандарте дисциплин и раскрываемых ими вопросов недостаточно для осуществления видов профессиональной деятельности бакалавра. В связи с этим, мы также не опровергаем то, что все бакалавры образования должны в обязательном порядке изучать дисциплину посвященную вопросу правовых основ сферы (области) образования (например, дисциплину «Образовательное право Республики Казахстан») [16].

В учебном плане на изучение некоторых дисциплин выделено большее количество часов. Поэтому существует реальная возможность введения дополнительных правовых дисциплин, не принижая значение других дисциплин в профессиональной подготовке. Кроме того, вуз имеет право самостоятельно определять перечень и содержание включаемых в учебный план дисциплин компонента по выбору базовых и профилирующих дисциплин. Содержание предлагаемых дисциплин должны разрабатываться в соответствии с квалификационной характеристикой выпускника и государственными требованиями к правовой компетентности студентов вузов по специальности 5В010800 - «Физическая культура и спорт».

Типовую учебную программу необходимо составлять с учетом профессиональноориентированного подхода. Например, программу для специальности 5В010800 «Физическая культура и спорт» необходимо составлять, в том числе, на основе законодательства Республики Казахстан в области физической культуры и спорта, с учетом практики его применения и достижений юридической науки. Преподавание правовых дисциплин должен носит теоретико-прикладной характер и предполагает ознакомление студентов с основами формирования образовательного и спортивного права.

Поскольку новые правовые дисциплины целесообразно вводить для студентов, начиная со второго курса (как правило, после уяснения общих положений основ права), изучение включенных в программу тем дает знания о современном содержании правового регулирования отношений, законодательства в области физической культуры и спорта, как нормативно-правовом образовании, о правовом положении субъектов физкультурно-спортивного движения, их правах, обязанностях и ответственности, ресурсном обеспечении физической культуры и спорта в Республике Казахстан, контроле за исполнением законов и иных нормативных правовых актов в области физической культуры и спорта. В конечном итоге полученные знания призваны способствовать лучшему уяснению студентами места и роли правового образования в структуре профессиональной подготовки.

Предусмотренная программа призвана играть большую роль в правовом образовании в профессиональной подготовке студентов будущих бакалавров образования по 
специальности 5В010800 - «Физическая культура и спорт», т.к. она - составная часть профессионального физкультурного образования. Правовые знания и умения призваны повысить качество подготовки специалистов для системы физической культуры и спорта в Республике Казахстан, и имеют не только базовое, но и непосредственное прикладное значение в их профессиональной деятельности.
Необходимая правовая компетентность студентов специальности 5В010800 «Физическая культура и спорт» обусловлена объективной потребностью - необходимостью достижения высокого качества и эффективности профессиональной деятельности при условии соблюдения законодательства Республики Казахстан.

\section{References:}

1. (2010) «Gosudarstvennaya programma razvitiya obrazovaniya Respubliki Kazakhstan na 2011 - 2020 gody» utverzhdennaya Ukazom Prezidenta Respubliki Kazakhstan ot 7 dec. 2010. №1118. Informatsionno-pravovaya sistema normativnykh pravovykh aktov Respubliki Kazakhstan «Odilet». Available: http://adilet.zan.kz/rus/docs/U1000001118

(Accessed: 22.05.2015).

2. Kalmenov GE (2001) Sovershenstvovanie podgotovki budushchikh uchiteley fizicheskoy kul'tury $\mathrm{k}$ professional'noy deyatel'nosti v kontekste novykh obrazovatel'nykh paradigm: avtoref. dis... kand. ped. nauk, A., 2001. - 20 p.

3. Malay LY (1993) Informatsionnopedagogicheskie zaprosy kak faktor povysheniya kvalifikatsii uchiteley (na materiale raboty fakul'teta fizicheskoy kul'tury i instituta usovershenstvovaniya): avtoref. dis... kand. ped. nauk, A., 1993. - 23 p.

4. Saparbaev MB (1993) Teoriya i praktika podgotovki uchiteley fizicheskoy kul'tury $\mathrm{v}$ sisteme nepreryvnogo pedagogicheskogo obrazovaniya: avtoref. dis... kand. ped. nauk, A., 1993. - 25 p.

5. Yumasheva ZA (2009) Tekhnologiya realizatsii sistemy upravleniya kachestvom obrazovaniya spetsial'nosti fizicheskaya kul'tura i sport: avtoref. dis... d-ra. ped. nauk, A., 2009. - 42 p.

6. Ageev SL (2012) Razvitie professional'noy kompetentnosti prepodavatelya fizicheskoy kul'tury $\mathrm{v}$ sisteme povysheniya kvalifikatsii: avtoref. dis... kand. ped. nauk, Chelyabinsk, 2012. - 23 p.

7. Voevodina SS (2002) Formirovanie pravovoy kompetentnosti studentov vuzov fizicheskoy kul'tury: Avtoref. dis... kand. ped. nauk, Krasnodar: KGAFK, 2002. -24p.

8. Kuznetsov SA (2011) Formirovanie sotsial'nopravovoy kompetentnosti u budushchikh spetsialistov po fizicheskoy kul'ture i sportu: avtoref. dis... kand ped. nauk, Cheboksary, 2011. - 23 p.

9. Sibatrova MA (2006) Formirovanie pravovoy obrazovannosti studentov vuza fizicheskoy kul'tury: avtoreferat dis. ... kandidata pedagogicheskikh nauk: 13.00.04 / Ur. gos. un-t fiz. Kul'tury Chelyabinsk, 2006.

10. Tochitskiy AV (2012) Professional'no-pravovoe samoobrazovanie spetsialistov po khokkeyu s shayboy: avtoreferat dis. ... kandidata pedagogicheskikh nauk: SPb, 2012.

11. Feoktistova OA (2010) Kontrol' znaniy studentov sportivnykh vuzov po distsipline «Pravovye osnovy fizicheskoy kul'tury i sporta» $\mathrm{s}$ ispol'zovaniem testovykh metodik (tekhnologiy): diss. kand. ped. nauk: Moscow.

12. Khurlet MA (2006) Razvitie pravovoy kul'tury studentov vuza fizicheskoy kul'tury: avtoreferat dis. ... kandidata pedagogicheskikh nauk, Chelyabinsk, 2006.

13. (2010) GOSO RK «Vysshee obrazovanie. Bakalavriat» po spetsial'nosti 5V010800 «Fizicheskaya kul'tura i sport». Astana, 2011.

14. (2009) «Tipovye kvalifikatsionnye kharakteristiki dolzhnostey pedagogicheskikh rabotnikov i priravnennykh $\mathrm{k}$ nim lits» utverzhdennye Prikazom Ministra obrazovaniya i nauki Respubliki Kazakhstan ot 13 july 2009 goda № 338. Informatsionno-pravovaya sistema normativnykh pravovykh aktov Respubliki Kazakhstan «Odilet». Available: http://adilet.zan.kz/rus/docs/V090005750 (Accessed: 22.05.2015).

15. (2015) Programma distsipliny «Pravovye osnovy fizicheskoy kul'tury i sporta B3.V.4.5» Ofitsial'nyy sayt Kazanskogo (Privolzhskogo) federal'nogo universiteta. Available: http://kpfu.ru/pdf/portal/oop/32124.pdf (Accessed: 22.05.2015).

16. Bermagambet R (2013) Perspektivy razvitiya obrazovatel'nogo zakonodatel'stva Respubliki Kazakhstan v ramkakh integratsii obrazovatel'nykh sistem gosudarstvuchastnikov SNG. Sadykovskie chteniya: problemy i puti vnedreniya innovatsionnykh tekhnologiy v obrazovatel'noe prostranstvo: materialy ISPC. - Almaty: KazNPU im. Abaya, 2013. - pp. 416. 